\title{
Screening and diagnosis of gestational diabetes mellitus in South Africa: What we know so far
}

\author{
S Dias, ${ }^{1,2}$ MSc (Molecular Biology); C Pheiffer, ${ }^{1,3} \mathrm{PhD}$ (Medical Biochemistry); P Rheeder, ${ }^{4}$ MB ChB, MMed (Int Med), FCP (SA), \\ MSc (Clin Epidemiology), PhD; S Adam, ${ }^{2} \mathrm{MB}$ ChB, FCOG (SA), MMed (O\&G), PhD, Cert Maternal and Fetal Medicine (SA) \\ ${ }^{1}$ Biomedical Research and Innovation Platform (BRIP), South African Medical Research Council, Cape Town, South Africa \\ ${ }^{2}$ Department of Obstetrics and Gynaecology, Faculty of Health Sciences, University of Pretoria, South Africa \\ ${ }^{3}$ Division of Medical Physiology, Department of Biomedical Sciences, Faculty of Medicine and Health Sciences, Stellenbosch University, \\ Cape Town, South Africa \\ ${ }^{4}$ Department of Internal Medicine, Faculty of Health Sciences, University of Pretoria, South Africa
}

Corresponding author: S Adam (sumaiya.adam@up.ac.za)

The early detection and management of gestational diabetes mellitus (GDM) present an ideal opportunity to decrease perinatal complications and adverse long-term health outcomes in mothers and their offspring. This review describes the major GDM screening and diagnostic strategies used worldwide, including novel screening and diagnostic methods that are being explored. It highlights the varied screening and diagnostic strategies currently employed in South Africa (SA). The lack of uniform GDM diagnostic criteria and variation in clinical practice hamper early detection and management of GDM, which negatively affects maternal and child health. We recommend that an SA diabetes-in-pregnancy study group, comprising interested obstetricians, physicians, endocrinologists, public health specialists, dieticians and scientists, be established to make evidence-based recommendations on affordable, accessible and applicable GDM screening and diagnostic and management strategies.

S Afr Med J 2019;109(7):457-462. DOI:10.7196/SAMJ.2019.v109i7.14064

Gestational diabetes mellitus (GDM) is defined as glucose intolerance with onset or first recognition during pregnancy. ${ }^{[1]}$ The prevalence of GDM has significantly increased over the past 20 years ${ }^{[2]}$ and in 2017 the International Diabetes Federation (IDF) estimated that $\sim 14 \%$ of pregnant women are affected by GDM, depending on the diagnostic criteria used and population studied. ${ }^{[3]}$ The World Health Organization (WHO) classifies pre-existing diabetes or newly diagnosed type 1 or type 2 diabetes as severe hyperglycaemia during pregnancy, while GDM represents a milder form of hyperglycaemia that occurs in the latter half of pregnancy and usually resolves after delivery. ${ }^{[4]}$ Without appropriate glucose management, GDM is associated with perinatal complications and an increased risk of future metabolic disease in mothers and their offspring.

The early detection and treatment of GDM are effective in preventing these adverse outcomes; therefore, universal screening and diagnosis of GDM are widely advocated as a strategy to promote appropriate treatment and improve pregnancy outcomes. The oral glucose tolerance test (OGTT) conducted at $24-28$ weeks of gestation is currently considered the gold standard for the diagnosis of GDM. ${ }^{[5]}$ However, the test is cumbersome to conduct, as well as time consuming, expensive and unfeasible in many low- and middle-income countries, resulting in many countries using risk factor-based selective screening. The lack of uniformity in GDM diagnosis and variations in clinical practice hamper its early detection and management, which negatively affect maternal and child health. Therefore, the identification of simple, cost-effective, sensitive and specific biomarkers, which do not require fasting and multiple sampling, may become potential screening and diagnostic tools and have become a major focus in GDM research. This review describes the major GDM screening and diagnostic strategies used worldwide, including novel screening and diagnostic methods that are being explored. It highlights the varied screening and diagnostic strategies currently employed in South Africa (SA). We also discuss challenges associated with these strategies and offer recommendations for future research.

\section{Screening tests}

The terms screening and diagnosis are often confusingly used interchangeably. ${ }^{[6]}$ Screening tests identify asymptomatic GDM in apparently healthy pregnant women, facilitating diagnosis and management. ${ }^{[7]}$ A negative screening test obviates the need for the cumbersome OGTT, the gold standard for GDM diagnosis, which is costly and is associated with multiple sampling, nausea and vomiting. Currently, screening for GDM is done by using traditional risk factors, ${ }^{\left[{ }^{[}\right]}$the $50 \mathrm{~g}$ glucose challenge test (GCT) or an OGTT. ${ }^{[6]}$ A number of other novel screening tests are being explored, including fasting plasma glucose, ${ }^{[9]}$ glycated haemoglobin (HbA1c), ${ }^{[10]}$ cytokines ${ }^{[11]}$ and molecular biomarkers, ${ }^{[12]}$ which are discussed in more detail below. Screening for traditional risk factors remains the cornerstone of screening strategies in low- and middleincome countries due to costs and ease. However, several studies ${ }^{[8,13-15]}$ have reported that risk factors have poor predictive value and fail to identify a large percentage of women with GDM, thus limiting their use. Adam et al ${ }^{[8]}$ reported that risk factors failed to identify $\sim 10.6 \%$ of pregnant women with GDM in SA. The GCT is commonly used to screen for GDM in the USA and involves administering a $50 \mathrm{~g}$ glucose load to pregnant women at $24-28$ weeks' gestation, irrespective of fasting. If their $1 \mathrm{~h}$ plasma glucose concentrations exceed predetermined cut-off values, usually $7.2 \mathrm{mmol} / \mathrm{L}$ or $7.8 \mathrm{mmol} / \mathrm{L}$, they are referred for GDM diagnosis. In 2010, the International Association of Diabetes in Pregnancy Study Groups (IADPSG) advocated for 'no 
screening' or 'universal testing', where all pregnant women undergo the diagnostic $75 \mathrm{~g}$ OGTT at $24-28$ weeks of gestation. ${ }^{[16]}$ Furthermore, the IADPSG decreased the threshold for diagnosing GDM (Table 1). These recommendations were based on findings from the Hyperglycemia and Adverse Pregnancy Outcome (HAPO) study that showed a linear correlation between maternal blood glucose concentrations and adverse pregnancy outcomes, even at glucose concentrations previously considered normal. ${ }^{[17]}$ The HAPO study assessed glucose concentrations and pregnancy complications in 23316 pregnant women across 9 countries; therefore, the IADPSG considered this evidence sufficient to alter the diagnostic criteria for GDM. A few years later, the WHO endorsed the IADPSG universal testing strategy, but remains sceptical owing to poor quality of evidence, increased costs and the possibility of overdiagnosis. ${ }^{[18]}$ Globally, there are no accepted screening criteria for GDM, and universal testing for diagnosing GDM remains the recommended strategy, although its implementation varies across countries and institutions.

\section{Diagnosis}

The OGTT is the gold standard for diagnosis of GDM. However, its use is not standardised worldwide and varies according to availability and access of standardised laboratories, resources, cost and GDM risk. The main issues of contention are whether a one-step or two-step procedure, which includes prior screening, is used, the glucose load $(75 \mathrm{~g}$ or $100 \mathrm{~g})$, duration of test $(2 \mathrm{~h}$ or $3 \mathrm{~h}$ ), glucose cut-off values, and whether diagnosis is based on one or two high glucose values. ${ }^{[18]}$ GDM diagnosis has evolved considerably over the years, with older criteria based mainly on managing longterm health outcomes, while more recent criteria focus on adverse perinatal outcomes. The landmark screening and diagnostic criteria for GDM are shown in Fig. 1. In 1964, O'Sullivan and Mahan ${ }^{[19]}$ proposed a two-step approach, which involved screening with the GCT, followed by a confirmatory $100 \mathrm{~g} 3 \mathrm{~h}$ OGTT in women who tested positive for screening. The National Diabetes Data Group (NDDG) ${ }^{[20]}$ and Carpenter and Coustan ${ }^{[21]}$ revised these criteria in 1979 and 1984, respectively, correcting for the higher glucose concentrations in plasma compared with venous blood that was originally used by O'Sullivan and Mahan. ${ }^{[19]}$ In 1985, the WHO recommended that a $75 \mathrm{~g} 2 \mathrm{~h}$ OGTT be performed to diagnose GDM, using the same thresholds as those for diagnosing diabetes in non-pregnant women. ${ }^{[22]}$ In 1999, the WHO revised their diagnostic criteria for GDM to include impaired glucose tolerance (IGT) and diabetes. ${ }^{[23]}$ The American Diabetes Association (ADA) adopted the Carpenter and Coustan ${ }^{[21]}$ criteria and recommended testing for GDM at 24 - 28 weeks' gestation using either a one-

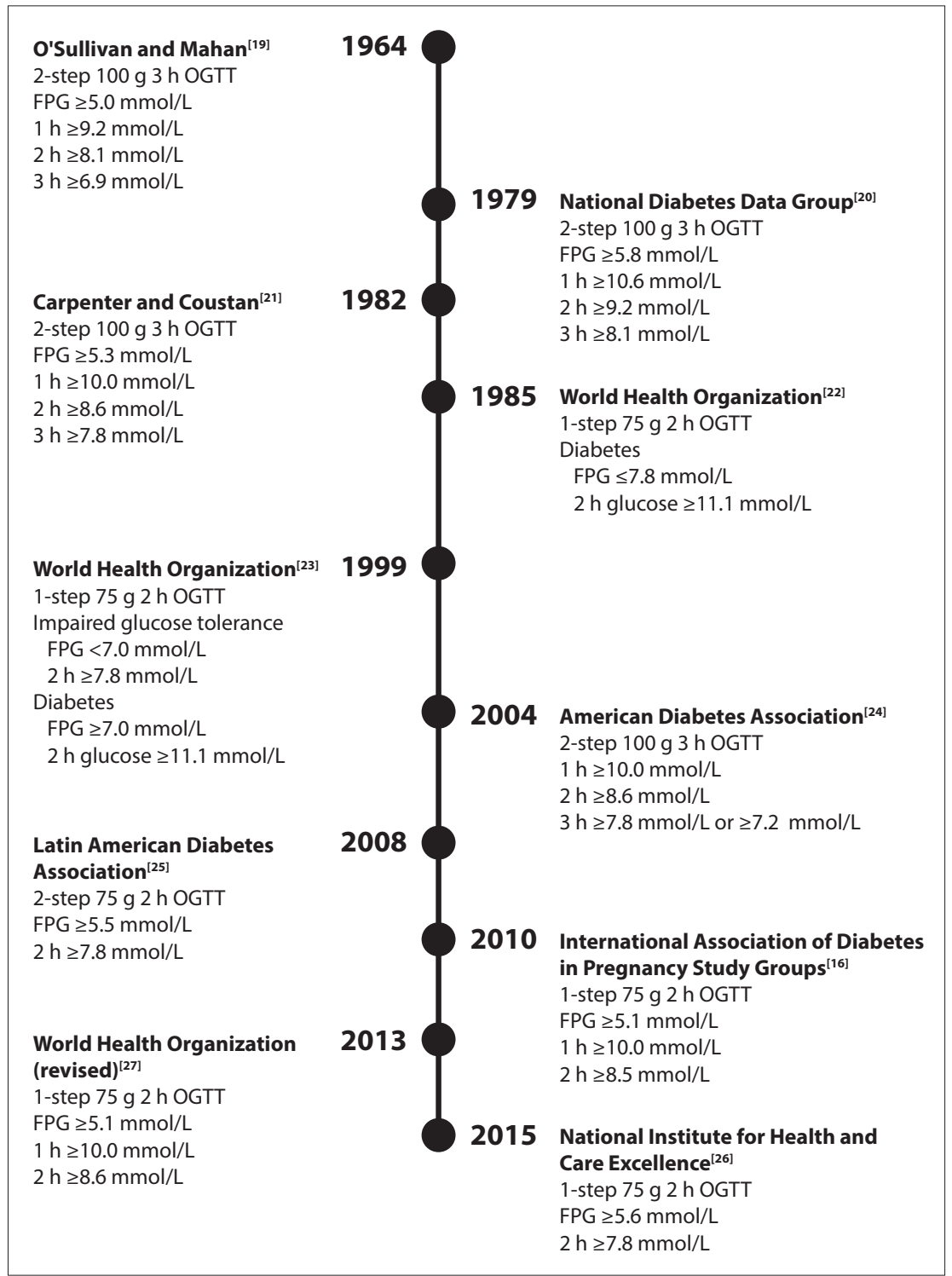

Fig. 1. The evolution of gestational diabetes mellitus screening and diagnosis between 1964 and 2015. (FPG = fasting plasma glucose; $O G T T=$ oral glucose tolerance test .

Table 1. Diagnostic criteria for gestational diabetes mellitus commonly used in South Africa

\begin{tabular}{|c|c|c|c|c|c|c|}
\hline Organisation & $\begin{array}{l}\text { Glucose } \\
\text { load, g }\end{array}$ & $\begin{array}{l}0 \mathrm{~h} \text { glucose, } \\
\mathrm{mmol} / \mathrm{L}\end{array}$ & $\begin{array}{l}1 \mathrm{~h} \text { glucose, } \\
\mathrm{mmol} / \mathrm{L}\end{array}$ & $\begin{array}{l}2 \mathrm{~h} \text { glucose, } \\
\mathrm{mmol} / \mathrm{L}\end{array}$ & $\begin{array}{l}3 \mathrm{~h} \text { glucose, } \\
\mathrm{mmol} / \mathrm{L}\end{array}$ & Values for diagnosis \\
\hline IADPSG/WHO/FIGO & 75 & 5.1 & 10 & 8.5 & - & $\geq 1$ \\
\hline NICE & 75 & 5.6 & - & 7.8 & - & $\geq 1$ \\
\hline ACOG & 100 & 5.3 & 10 & 8.6 & 7.8 & $\geq 2$ \\
\hline WHO 1999 & 75 & 7.0 & - & 7.8 & - & $\geq 1$ \\
\hline
\end{tabular}


step approach with the $100 \mathrm{~g}$ OGTT or a two-step procedure with the GCT, followed by a diagnostic $100 \mathrm{~g}$ OGTT. ${ }^{[24]}$ In the final report of the Pan American Conference on Diabetes and Pregnancy, the Latin American Diabetes Association (LADA) criteria were proposed for the diagnosis of GDM in selected countries of South America, using a two-step approach with a $75 \mathrm{~g} 2 \mathrm{~h}$ OGTT ${ }^{[25]}$ In 2010 , as previously described, the IADPSG proposed universal testing, where a one-step $75 \mathrm{~g} 2 \mathrm{~h}$ OGTT is conducted for all pregnant women at $24-28$ weeks' gestation. ${ }^{[5]}$ In 2013, the WHO revised their criteria and endorsed those of the IADPGS ${ }^{[4]}$ The National Institute for Health and Care Excellence (NICE) criteria are based on the WHO 1999 criteria, where GDM is diagnosed as IGT using the $75 \mathrm{~g} 2 \mathrm{~h}$ OGTT. ${ }^{[26]}$ They have not adopted the new recommended IADPSG/WHO 2013 diagnostic criteria, as evidence suggests relatively small differences in clinical outcomes and increased cost implications. ${ }^{[27]}$ Currently, the International Federation of Gynecology and Obstetrics (FIGO) guidelines ${ }^{[1]}$ recommend the use of a glucometer for point-of-care diagnosis of GDM in limited-resource settings due to its low cost, ease of use and ability to diagnose and treat GDM at the earliest possible opportunity. However, a study investigating the performance of the glucometer diagnosis of GDM compared with the gold standard laboratory test showed poor correlation and reproducibility when GDM was diagnosed using the FIGO criteria. ${ }^{[28]}$

\section{Novel screening and diagnostic strategies \\ Glucose}

Measurement of fasting glucose concentrations has shown promise as a screening ${ }^{[29]}$ and diagnostic test; ${ }^{[8,30]}$ however, the test requires pregnant women to be in a fasted state and return to the clinic to obtain their laboratory results. ${ }^{[9]}$ Measurement of random glucose and $\mathrm{HbA1c}$ levels obviates the need for fasting and has been explored as alternative screening and diagnostic tests. ${ }^{[31]} \mathrm{HbAlc}$, a measurement of the amount of glucose bound to haemoglobin, is currently the gold standard for long-term blood glucose monitoring. However, it is affected by factors such as ethnicity, anaemia, haemodilation or other blood disorders that hamper its accuracy as a diagnostic tool for GDM. ${ }^{[31-33]}$ Therefore, although these tests are convenient, fast, simple, inexpensive and can be done at point of care, the results are inconsistent, with low sensitivity and specificity, and have been unsuccessful to date.

Other novel strategies investigated in the SA population include the 'breakfast test' - a non-standardised glucose load administered to pregnant women - instead of the OGTT. ${ }^{[34]}$ Because of the variability in carbohydrate content with a non-standardised glucose load, ${ }^{[35]}$ the breakfast test was revised to include a standardised carbohydrate content that is equivalent to the $75 \mathrm{~g}$ OGTT. Marais et al. ${ }^{[34]}$ reported a correlation between blood glucose values obtained using the designed breakfast test and values obtained using the OGTT. These and other results suggest that a standardised breakfast test that is more palatable than the OGTT may offer an alternative method for assessing hyperglycaemia during pregnancy. ${ }^{[36-38]}$

\section{Serum proteins}

Adaptation to metabolic stress during pregnancy is reflected by changes in the expression of maternal proteins. These proteins are readily detected in plasma or serum and have recently attracted considerable interest as potential screening and diagnostic proteins for GDM. Several studies have reported on the potential of maternal plasma or serum biomarkers, such as adiponectin, sex hormonebinding globulin (SHBG), C-reactive protein (CRP) and glycosylated fibronectin, as biomarkers of GDM. ${ }^{[39-41]}$ Nanda et al. ${ }^{[39]}$ reported that maternal serum adiponectin and SHBG levels at $11-13$ weeks of gestation were lower in women with GDM than in controls. Similarly, Smirnakis et al. ${ }^{[41]}$ reported lower levels of serum SHBG and higher levels of CRP during the first and second trimesters in pregnant women who subsequently developed GDM. Furthermore, glycosylated fibronectin, adiponectin, CRP and human placental lactogen (hPL) concentrations at 5 - 13 weeks of gestation were shown to be associated with GDM. ${ }^{[40]}$ Together, these studies demonstrate that maternal proteins represent a promising first- and secondtrimester screening test to identify women at risk of developing GDM. Further prospective studies are required to investigate the clinical applicability of these biomarkers.

\section{Genetics}

Variants in genes regulating glucose homeostasis are increasingly being implicated in the pathogenesis of GDM and thus present candidates for biomarkers of disease pathophysiology. ${ }^{[42]}$ To date, genetic studies have identified 8 genes commonly associated with the development of GDM in $\geq 2$ independent populations. While genetic variants have been identified in other genes associated with GDM, these were only demonstrated in single populations. ${ }^{[12]}$ The genes identified in $\geq 2$ independent populations include transcription factor 7-like 2 (TCF7L2), adiponectin $(A D I P O Q)$, melatonin-receptor $1 \mathrm{~B}$ gene $(M T N R 1 B)$, glucokinase $(G C K)$, glucokinase regulator $(G C K R)$, fat mass and obesity-associated (FTO), insulin-receptor substrate 1 (IRS1) and potassium voltage-gated channel subfamily Q member 1 (KCNQ). Due to variation across different populations, further studies are needed to confirm the association between risk alleles and GDM. Further analysis in diverse ethnic groups is required to examine whether these risk variants can be used as biomarkers to predict the development of GDM. Despite the association between genetics and GDM, the important role of the environment in GDM susceptibility is increasingly being recognised.

\section{Epigenetics}

Epigenetics is defined as changes in gene expression that occur without changes in the underlying DNA sequence. ${ }^{[33]}$ These changes reflect gene-environment interactions and are increasingly being implicated in the pathophysiology of metabolic diseases. ${ }^{[44,45]}$ Epigenetic mechanisms include DNA methylation, chromatin and histone modifications, and non-coding RNAs such as microRNAs (miRNAs). DNA methylation is the most widely studied and best characterised epigenetic mechanism, and refers to the addition of a methyl group to the fifth carbon position of a cytosine nucleotide, often leading to transcriptional repression. ${ }^{[46]}$ DNA methylation plays a key role in regulating genes involved in metabolic adaptation during pregnancy, ${ }^{[47]}$ and aberrant DNA methylation is implicated in the pathophysiology of GDM. Altered DNA methylation patterns have been demonstrated in maternal blood, placental tissue and cord blood of GDM-complicated pregnancies, thus supporting its potential as biomarkers. ${ }^{[48-53]}$

Wu et al. ${ }^{[54]}$ demonstrated that two genes, Hook microtubuletethering protein 2 (HOOK2) and retinol dehydrogenase 12 (RDH12), are differentially methylated in placenta and whole blood of women with GDM. Interestingly, the changes in methylation status of these genes in whole blood occurred prior to the development of GDM, supporting their potential as screening biomarkers of GDM. In a study investigating maternal and cord blood in pregnant women and their offspring, Kang et al. ${ }^{[55]}$ identified 200 genes that were differentially methylated in women with GDM compared with controls. Conversely, our recent study ${ }^{[56]}$ showed no differences in global DNA methylation between pregnant women with GDM and 
those with normoglycaemia in SA. Global DNA methylation is a robust marker for overall genomic methylation; therefore, our failure could be due to subtle methylation differences between GDM and control groups. Perhaps, a more targeted approach using genomewide gene-specific DNA methylation should be considered. Together, these studies show that altered DNA methylation in different biological material plays an important role in the pathophysiology of GDM and offers opportunities as biomarkers.

Another epigenetic mechanism widely explored as a biomarker for $\mathrm{GDM},{ }^{[57]}$ i.e. miRNAs, has been shown to post-transcriptionally regulate genes involved in diverse biological processes, including glucose homeostasis. ${ }^{[58]}$ Placental miRNA expression reflects metabolic adaptation, with aberrant expression observed during GDM. Interestingly, the expression of many of these altered miRNAs is mirrored in serum or plasma, thus offering potential as biomarkers for GDM. Zhao et al. ${ }^{[59]}$ reported that the expression of miR-29a and miR-222, miRNAs that are involved in insulin sensitivity, glucose homeostasis and beta-cell function, are decreased in serum of Chinese women with GDM compared with pregnant women without GDM. Pheiffer et al. ${ }^{[60]}$ similarly reported that the expression of miR-222 is decreased in the serum of SA women with GDM. They also reported the decreased expression of miR-20a, which was a significant predictor of GDM. Conversely, Tagoma et al. ${ }^{[61]}$ reported increased expression of plasma-derived miR-222 in Finnish women with GDM compared with controls, while miR-20a was increased in Chinese women with GDM compared with controls. ${ }^{[62]}$ Furthermore, many studies have demonstrated that placenta-specific miRNAs are altered in pregnancy complications, such as preeclampsia, macrosomia, preterm delivery, pregnancy loss and smallfor-gestational-age babies, which further supports the use of miRNAs as predictive biomarkers for adverse pregnancy outcomes. ${ }^{[63,64]}$

GDM creates an abnormal intrauterine environment that negatively affects the long-term health of offspring, possibly through in utero programming of epigenetic mechanisms such as DNA methylation and miRNAs. ${ }^{[52,65-67]}$ Using genome-wide methylation analysis, Heartle et al ${ }^{[52]}$ identified $65 \mathrm{CpG}$ sites associated with 52 genes that were differentially methylated in fetal cord blood from GDM and control pregnancies. Of these, 5 candidate genes that play a role in metabolic pathways associated with oxidative damage, cardiovascular complications, glucose and amino-acid metabolisms and adipocyte differentiation were validated. El Hajj et al. ${ }^{[65]}$ showed gene-specific methylation changes in the maternally imprinted MESH gene and the non-imprinted glucocorticoid receptor (NR3C1) gene in both cord blood and placental tissue of GDM groups compared with controls. Recently, altered miRNA expression in the cord blood of offspring was shown to be associated with fetal complications. ${ }^{[6]]}$ Tryggestad et al. ${ }^{[67]}$ indicated that 7 miRNAs were upregulated in human umbilical vein endothelial cells from infants born to mothers with GDM. Despite their stability, relative ease of quantification and affordability, DNA methylation and miRNAs present several challenges that hinder their reproducibility across studies. Future research should explore risk-scoring systems that can be used to combine molecular markers with maternal risk indicators to develop a clinical prediction tool for GDM.

\section{Screening and diagnosis in South Africa}

The four most common diagnostic criteria used in SA are the IADPSG, NICE, American College of Obstetricians and Gynecologists (ACOG) and WHO 1999 criteria (Table 1). In 2017, the Society for Endocrinology, Metabolism and Diabetes of South Africa (SEMDSA) endorsed the IADPSG criteria and universal testing of all pregnant women. ${ }^{[68]}$ However, the IADPSG criteria are still being debated, as many clinicians consider these unfeasible in low- and middle-income countries such as SA. Their view is that it leads to overdiagnosis, and places a high demand on costs, workload and resources. Therefore, many local and regional health facilities continue to use risk-factor, selective IADPSG, NICE, ACOG or WHO 1999 criteria (Table 2). ${ }^{[69]}$

\section{Current perspectives and future recommendations}

- Early screening and diagnosis of GDM improve health outcomes.

- Although the OGTT is the gold standard for diagnosis, there is no consensus, and GDM diagnosis is not standardised.

- Novel screening and diagnostic strategies offer potential as biomarkers of GDM, but are yet to achieve clinical applicability.

Table 2. Current approach to gestational diabetes mellitus screening at select academic centres in South Africa*

\begin{tabular}{|c|c|c|c|c|c|}
\hline Institution & Testing & Diagnostic criteria & Level of screening & $\begin{array}{l}\text { Glucometer v. } \\
\text { laboratory }\end{array}$ & GDM management $^{\dagger}$ \\
\hline UP & Selective ${ }^{*}$ & WHO 2013 & Clinic and hospital & $\begin{array}{l}\text { Glucometer and } \\
\text { laboratory }\end{array}$ & Tertiary hospital \\
\hline WITS & Selective $^{\ddagger}$ & NICE & Hospital & Laboratory & Tertiary hospital \\
\hline UKZN & $\begin{array}{l}\text { Selective }^{\ddagger} \text { and } \\
\text { universal }^{\S} \text { for } \\
\text { R K Khan Hospital } \\
\text { (Indian) }\end{array}$ & WHO 2013 & Hospital & Laboratory & Tertiary hospital \\
\hline UCT & Selective ${ }^{\ddagger}$ & WHO 2013 & Hospital & Laboratory & Tertiary hospital \\
\hline SU & Selective ${ }^{*}$ & NICE & Clinic and hospital & Glucometer & Tertiary hospital \\
\hline UFS & Selective ${ }^{\ddagger}$ & IADPSG/WHO 2013 & Clinic and hospital & $\begin{array}{l}\text { Glucometer and } \\
\text { laboratory }\end{array}$ & Tertiary hospital \\
\hline SMU & Selective & Modified WHO' & Hospital & Laboratory & Tertiary hospital \\
\hline Walter Sisulu & Selective ${ }^{*}$ & WHO 2013 & Hospital & Laboratory & Tertiary hospital \\
\hline \multicolumn{6}{|c|}{$\begin{array}{l}\text { GDM = gestational diabetes mellitus; UP = University of Pretoria; WHO = World Health Organization; WITS = University of the Witwatersrand; } \\
\text { NICE = National Institute for Health and Care Excellence; UKZN = University of KwaZulu-Natal; UCT = University of Cape Town; SU = Stellenbosch University; } \\
\text { UFS = University of the Free State; IADPSG = International Association of Diabetes in Pregnancy Study Groups; SMU = Sefako Makgatho Health Sciences University. } \\
\text { *The details of this table were communicated with individuals of the respective institutes between September and November 2018. } \\
\text { "All women with a positive oral glucose tolerance test are referred to a tertiary hospital for management of GDM. } \\
\text { "Based on risk factors. } \\
\text { sAll women receive an oral glucose tolerance test. } \\
\text { 'The institute's own version of the WHO criteria, which have not yet been published. }\end{array}$} \\
\hline
\end{tabular}


- Future longitudinal studies across SA are required to assess the risks and benefits of diagnostic criteria and pregnancy outcomes.

- Experts are needed to establish and co-ordinate such initiatives and to make evidence-based recommendations on GDM screening and diagnosis.

\section{Conclusions}

We have highlighted the varied screening and diagnostic strategies currently employed in SA. Although universal screening and diagnosis of GDM are widely advocated as a strategy to promote appropriate treatment and improve pregnancy outcomes, it is not feasible in many low- and middle-income countries, resulting in many countries using risk factor-based selective screening. The lack of uniform GDM screening and diagnostic criteria and variation in clinical practice negatively affect maternal and child health. There is limited evidence to support one approach over the other. There is a need for longitudinal studies across SA to investigate the association between their diagnostic criteria and pregnancy outcomes, as well as long-term outcomes in mothers and their offspring. We recommend that an SA diabetes-in-pregnancy study group, comprising interested obstetricians, physicians, endocrinologists, public health specialists, dieticians and scientists, be established to co-ordinate such initiatives and to make evidence-based recommendations on GDM screening, diagnosis and management.

Declaration. This publication forms part of SD's $\mathrm{PhD}$ degree that will be submitted to the University of Pretoria.

Acknowledgements. The authors would like to thank all selected academic centres in SA for their contribution regarding information for this review. Author contributions. All authors contributed to the compilation and writing of this article; $\mathrm{CP}$ and SA conceived the idea for the review; SD wrote the manuscript; and all authors reviewed and edited the draft and approved the final manuscript.

Funding. This work was supported by the National Research Foundation of South Africa (unique grant no. 99391), and by baseline funding from the South African Medical Research Council (SAMRC).

Conflicts of interest. None.

1. Hod M, Kapur A, Sacks DA, et al. The International Federation of Gynecology and Obstetrics (FIGO) initiative on gestational diabetes mellitus: A pragmatic guide for diagnosis, management, and care. initiative on gestational diabetes mellitus: A pragmatic guide for diagnosis, management, and care
Int J Gynecol Obstet 2015;131(Suppl 3):S173-S211. https://doi.org/10.1016/s0020-7292(15)30033-3

2. Ferrara A. Increasing prevalence of gestational diabetes mellitus: A public health perspective. Diabet Ferrara A. Increasing prevalence of gestational diabetes mellitus: A p
Care 2007;30(Suppl 2):S141-S146. https://doi.org/10.2337/dc07-s206

3. International Diabetes Federation. IDF diabetes atlas - across the globe. 2017. http://diabetesatlas.org/ across-the-globe.html (accessed 6 May 2019).

4. World Health Organization. Diagnostic Criteria and Classification of Hyperglycaemia First Detected in Pregnancy. Geneva: WHO, 2013.

5. Metzger Boyed E, Persson B, IADPSG panel, Gabbe SG. International association of diabetes and pregnancy study groups recommendations on the diagnosis and classification of hyperglycemia in pregnancy. Diabet Care 2010;33(3):676. https://doi.org/10.2337/dc09-1848

6. Sacks DB. Diagnosis of gestational diabetes mellitus: It is time for international consensus. Clin Chem 2014;60(1):141-143. https://doi.org/10.1373/clinchem.2013.206920

7. Hartling L, Dryden DM, Guthrie A, et al. Screening and diagnosing gestational diabetes mellitus. Evid Rep Technol Assess (Full Rep) 2012;21:32-41.

8. Adam S, Rheeder P. Screening for gestational diabetes mellitus in a South African population: Prevalence, comparison of diagnostic criteria and the role of risk factors. S Afr Med J 2017;107(6):523Prevalence, comparison of diagnostic criteria and the
527. https://doi.org/10.7196/samj.2017.v107i6.12043

9. Agarwal MM. Gestational diabetes mellitus: Screening with fasting plasma glucose. World J Diabet Agarwal MM. Gestational diabetes mellitus: Screening with
2016;7(14):279-289. https://doi.org/10.4239/wjd.v7.i14.279

10. Khalafallah A, Phuah E, Al-Barazan AM, et al. Glycosylated haemoglobin for screening and diagnosis of gestational diabetes mellitus. BMJ Open 2016;6(4):e011059. https://doi.org/10.1093/ageing/22.1.70

11. Abell SK, de Courten B, Boyle JA, Teede HJ. Inflammatory and other biomarkers: Role in pathophysiology and prediction of gestational diabetes mellitus. Int J Mol Sci 2015;16(6):13442-13473. https://doi.org/10.3390/ijms160613442

12. Dias S, Pheiffer C, Abrahams Y, Rheeder P, Adam S. Molecular biomarkers for gestational diabetes mellitus. Int J Mol Sci 2018;19(10). https://doi.org/10.3390/jms19102926

13. Matta-Coelho C, Monteiro AM, Fernandes V, Pereira ML, Souto SB, Portuguese Diabetes and Pregnancy Study Group. Universal vs. risk-factor-based screening for gestational diabetes - an analysis from a 5-year Portuguese cohort. Endocrine 2019;63(3):507-512. https://doi.org/10.1007/s12020-018$1760-8$

14. Agbozo F, Abubakari A, Narh C, Jahn A. Accuracy of glycosuria, random blood glucose and risk factors as selective screening tools for gestational diabetes mellitus in comparison with universal diagnosing. BMJ Open Diabet Res Care 2018;6(1):e000493. https://doi.org/10.1136/bmjdrc-2017-000493
15. Miailhe G, Kayem G, Girard G, Legardeur H, Mandelbrot L. Selective rather than universal screening for gestational diabetes mellitus? Eur J Obstet Gynecol Reprod Biol 2015;191:95-100. https://doi org/10.1016/s1262-3636(07)70260-4

16. International Association of Diabetes and Pregnancy Study Groups Consensus Panel. IADPSG 2010;33(3):676-682

17. HAPO Study Cooperative Research Group, Metzger BE, Lowe LP, et al. Hyperglycemia and adverse pregnancy outcomes. N Engl J Med 2008;358(19):1991-2002. https://doi.org/10.1097/01. sa.0000318681.02582.c6

18. Sacks DB, Coustan DR, Cundy T, Donovan L, Hod M. Gestational diabetes mellitus: Why the controversy? Clin Chem 2018;64(3):431-438. https://doi.org/10.1373/clinchem.2016.266577

19. O'Sullivan JB, Mahan CM. Criteria for the oral glucose tolerance test in pregnancy. Diabetes 1964;13:278-285. https://doi.org/10.2337/diacare.24.7.1129

20. National Diabetes Data Group. Classification and diagnosis of diabetes mellitus and other categories of glucose intolerance. Diabetes 1979;28(12):1039-1057. https://doi.org/10.2337/diab.28.12.1039

21. Carpenter MW, Coustan DR. Criteria for screening tests for gestational diabetes. Am J Obstet Gynecol 1982;144(7):768-773. https://doi.org/10.1016/0002-9378(82)90349-0

22. World Health Organization. Diabetes Mellitus: Report of a WHO Study Group. Geneva: WHO, 1985.
23. World Health Organization. Definition, Diagnosis and Classification of Diabetes Mellitus and its World Health Organization. Definition,
Complications. Geneva: WHO, 1999.

24. American Diabetes Association. Diagnosis and classification of diabetes mellitus. Diabet Care 2004;27(Suppl 1):S5-S10. https://doi.org/10.2337/diacare.21.1.s5

25. Pan American Health Organization. Criteria for the diagnosis of gestational diabetes in selected countrie of the Americas. Final report of the Pan American Conference on Diabetes and Pregnancy, 8 - 10 September 2015, Lima, Peru. http://iris.paho.org/xmlui/bitstream/handle/123456789/28208/9789275118832_eng pdf? sequence=1\&isAllowed=y (accessed 22 May 2019).

26. National Institute for Health and Care Excellence. Diabetes in pregnancy: Management from preconception to the postnatal period. NICE Guidelines. 2015. https://www.nice.org.uk/guidance/ng3 (accessed 15 June 2018).

27. Jacklin PB, Maresh MJ, Patterson CC, et al. A cost-effectiveness comparison of the NICE 2015 and WHO 2013 diagnostic criteria for women with gestational diabetes with and without risk factors. BMJ Open 2017;7(8):e016621. https://doi.org/10.1136/bmjopen-2017-016621

28. Adam S, Rheeder P. Evaluating the utility of a point-of-care glucometer for the diagnosis of gestational Adam S, Rheeder P. Evaluating the utility of a point-of-care glucometer for the diagn
diabetes. Int J Gynecol Obstet 2018;141(1):91-96. https://doi.org/10.1002/iigo.12399

29. Agarwal MM, Punnose J, Dhatt GS. Gestational diabetes: Problems associated with the oral glucose Agarwal MM, Punnose J, Dhatt GS. Gestational diabetes: Problems associated with the oral glucose
tolerance test. Diabet Res Clin Pract 2004;63(1):73-74. https://doi.org/10.1016/j.diabres.2003.08.005 30. Macaulay S, Ngobeni M, Dunger DB, Norris SA. The prevalence of gestational diabetes mellitus amongs black South African women is a public health concern. Diabet Res Clin Pract 2018;139:278-287. https:// doi.org/10.1016/j.diabres.2018.03.012

31. Amreen S, Suneel A, Shetty A, Vasudeva A, Kumar P. Use of glycosylated HbAlc and random blood sugar as a screening tool for gestational diabetes mellitus in first trimester. Int $J$ Reprod Contracept Obstet Gynecol 2018;7(2):524-528. https://doi.org/10.18203/2320-1770.ijrcog20180166

32. Hughes RCE, Rowan J, Florkowski CM. Is there a role for HbAlc in pregnancy? Curr Diab Rep 2016;16(1):5. https://doi.org/10.1007/s11892-015-0698-y

33. Nguyen KA, Peer N, de Villiers A, et al. Glycated haemoglobin threshold for dysglycaemia screening, and application to metabolic syndrome diagnosis in HIV-infected Africans. PLOS ONE 2019;14(1)::0211483. https://doi.org/10.1371/journal.pone.0211483

34. Marais C, Hall DR, van Wyk L, Conradie M. Randomized cross-over trial comparing the diagnosis Marais C, Hall DR, van Wyk L, Conradie M. Randomized cross-over trial comparing the diagnosis
of gestational diabetes by oral glucose tolerance test and a designed breakfast glucose profile. Int J of gestational diabetes by oral glucose tolerance test and a designed
Gynecol Obstet 2018;141(1):85-90. https://doi.org/10.1002/ijgo.12427

35. Marais C, van Wyk L, Conradie M, Hall D. Screening for gestational diabetes: Examining a breakfast meal test. S Afr J Clin Nutr 2016;29(3):118-121. https://doi.org/10.1080/16070658.2016.1198614

36. Sutherland HW, Pearson DWM, Lean MEJ, Campbell DM. Breakfast tolerance test in pregnancy. In: Sutherland HW, Stowers JM, Pearson DWM, eds. Carbohydrate Metabolism in Pregnancy and the Newborn IV. London: Springer, 1989

37. Rey E. Usefulness of a breakfast test in the management of women with gestational diabetes. Obstet Gynecol 1997;89(6):981-988. https://doi.org/10.1016/s0029-7844(97)00141-5

38. Ramezani LEZ. Evaluation of a breakfast as screening test for the detection of gestational diabetes. Acta Med Iran 2008;46(1):43-46.

39. Nanda S, Savvidou M, Syngelaki A, Akolekar R, Nicolaides KH. Prediction of gestational diabetes mellitus by maternal factors and biomarkers at 11 to 13 weeks. Prenatal Diag 2011;31(2):135-141. https://doi.org/10.1002/pd.2636

40. Rasanen JP, Snyder CK, Rao PV, et al. Glycosylated fibronectin as a first-trimester biomarker for prediction of gestational diabetes. Obstet Gynecol 2013;122(3):586-594. https://doi.org/10.1097/ aog.0b013e3182a0c88b

41. Smirnakis KV, Plati A, Wolf M, Thadhani R, Ecker JL. Predicting gestational diabetes: Choosing the optimal early serum marker. Am J Obstet Gynecol 2007;196(4):410.e1-e6. https://doi.org/10.1016/j. ajog.2006.12.011

42. Wu L, Cui L, Tam WH, Ma RCW, Wang CC. Genetic variants associated with gestational diabetes mellitus: A meta-analysis and subgroup analysis. Sci Rep 2016;29(6):30539. https://doi.org/10.1038/srep30539 43. Christensen BC, Marsit CJ. Epigenomics in environmental health. Front Genet Media SA 2011;2(2):84 https://doi.org/10.3389/fgene.2011.00084

44. Martín-Núñez GM, Rubio-Martín E, Cabrera-Mulero R, et al. Type 2 diabetes mellitus in relation to global LINE-1 DNA methylation in peripheral blood: A cohort study. Epigenetics 2014;9(10):1322-1328. https://doi.org/10.4161/15592294.2014.969617

45. Gu T, Gu HF, Hilding A, et al. Increased DNA methylation levels of the insulin-like growth factor binding protein 1 gene are associated with type 2 diabetes in Swedish men. Clin Epigenet 2013;5(1):21. https://doi.org/10.1186/1868-7083-5-21

46. Lim DHK, Maher ER. DNA methylation: A form of epigenetic control of gene expression. Obstet Gynaecol 2010;12(1):37-42. https://doi.org/10.1576/toag.12.1.037.27556

47. Houde A-A, Guay S-P, Desgagné V, et al. Adaptations of placental and cord blood ABCA1 DNA methylation profile to maternal metabolic status. Epigenetics 2013;8(12):1289-1302. https://doi. org/10.4161/epi.26554

48. Nomura Y, Lambertini L, Rialdi A, et al. Global methylation in the placenta and umbilical cord blood from pregnancies with maternal gestational diabetes, preeclampsia, and obesity. Reprod Sci 2014;21(1):131-137. https://doi.org/10.1177/1933719113492206

49. Ruchat S-M, Houde A-A, Voisin G, et al. Gestational diabetes mellitus epigenetically affects genes predominantly involved in metabolic diseases. Epigenetics 2013;8(9):935-943. https://doi.org 10.1016/j.jcjd.2013.03.150

50. Lesseur C, Armstrong DA, Paquette AG, Li Z, Padbury JF, Marsit CJ. Maternal obesity and gestational diabetes are associated with placental leptin DNA methylation. Am J Obstet Gynecol 2014;211(6):654 el-e9. https://doi.org/10.1016/j.ajog.2014.06.037

51. Finer S, Mathews C, Lowe R, et al. Maternal gestational diabetes is associated with genome-wide DNA methylation variation in placenta and cord blood of exposed offspring. Hum Mol Genet 2015;24(11):3021-3029. https://doi.org/10.1093/hmg/ddv013

52. Haertle L, El Hajj N, Dittrich M, et al. Epigenetic signatures of gestational diabetes mellitus on cord blood methylation. Clin Epigenet 2017;9(1):28. https://doi.org/10.1186/s13148-017-0329-3 
53. Reichetzeder C, Dwi Putra SE, Pfab T, et al. Increased global placental DNA methylation levels are associated with gestational diabetes. Clin Epigenet 2016;8:82. https://doi.org/10.1186/s13148-016$0247-9$

54. Wu P, Farrell WE, Haworth KE, et al. Maternal genome-wide DNA methylation profiling in gestational diabetes shows distinctive disease-associated changes relative to matched healthy pregnancies. Epigenetics 2018;13(2):122-128. https://doi.org/10.1080/15592294.2016.1166321

55. Kang J, Lee C-N, Li H-Y, Hsu K-H, Lin S-Y. Genome-wide DNA methylation variation in maternal and cord blood of gestational diabetes population. Diabet Res Clin Pract 2017;132:127-136. https:// doi.org/10.1016/j.diabres.2017.07.034

56. Dias S, Adam S, van Wyk N, Rheeder P, Louw J, Pheiffer C. Global DNA methylation profiling in peripheral blood cells of South African women with gestational diabetes mellitus. Biomarkers 2019;24(3):225-231. https://doi.org/10.1080/1354750X.2018.1539770

57. Ge Q, Zhu Y, Li H, Tian F, Xie X, Bai Y. Differential expression of circulating miRNAs in maternal plasma in pregnancies with fetal macrosomia. Int J Molec Med 2015;35(1):81-91. https://doi.org/ 10.3892/ijmm. 2014.1989

58. Bartel DP. MicroRNAs: Genomics, biogenesis, mechanism, and function. Cell 2004;116(2):281-297.

59. Zhao C, Dong J, Jiang T, et al. Early second-trimester serum mirna profiling predicts gestational diabetes mellitus. PLOS ONE 2011;6(8):e23925. https://doi.org/10.1371/journal.pone.0023925

60. Pheiffer C, Dias S, Rheeder P, Adam S. Decreased expression of circulating mir-20a-5p in South African women with gestational diabetes mellitus. Molec Diag Ther 2018;22(3):345-352. https://doi. African women with gestational
org $/ 10.1007 /$ s40291-018-0325-0

61. Tagoma A, Alnek K, Kirss A, Uibo R, Haller-Kikkatalo K. MicroRNA profiling of second trimester maternal plasma shows upregulation of miR-195-5p in patients with gestational diabetes. Gen 2018;672:137-142. https://doi.org/10.1016/j.gene.2018.06.004

62. Zhu Y, Tian F, Li H, Zhou Y, Lu J, Ge Q. Profiling maternal plasma microRNA expression in early pregnancy to predict gestational diabetes mellitus. Int J Gynecol Obstet 2015;130(1):49-53. https://dol org/10.1016/j.ijgo.2015.01.010
63. Barchitta M, Maugeri A, Quattrocchi A, Agrifoglio O, Agodi A. The role of miRNAs as biomarkers for pregnancy outcomes: A comprehensive review. Int J Genomics 2017;2017:1-11. https://doi, for pregnancy outcomes:
org/10.1155/2017/8067972

64. Guarino E, Poggi CD, Grieco GE, et al. Circulating microRNAs as biomarkers of gestational diabetes mellitus: Updates and perspectives. Int J Endocrinol 2018. https://doi.org/10.1155/2018/6380463

65. El Hajj N, Pliushch G, Schneider E, et al. Metabolic programming of MEST DNA methylation by intrauterine exposure to gestational diabetes mellitus. Diabetes 2013;62(4):1320-1328. https://doi. org $/ 10.2337 / \mathrm{db} 12-0289$

66. Tsai P-Y, Li S-H, Chen W-N, Tsai H-L, Su M-T. Differential miR-346 and miR-582-3p expression in association with selected maternal and fetal complications. Int J Mol Sci 2017;18(7):E1570. https://doi. org/10.3390/ijms 18071570

67. Tryggestad JB, Vishwanath A, Jiang S, et al. Influence of gestational diabetes mellitus on human umbilical vein endothelial cell miRNA. Clin Sci 2016;130(21):1955-1967. https://doi.org/10.1042/ cs20160305

68. Society for Endocrinology, Metabolism and Diabetes of South Africa Type 2 Diabetes Guidelines Expert Committee. The 2017 SEMDSA guidelines for the management of type 2 diabetes. J Endocrinol Metab Diabet S Afr 2017;21(1)(Suppl 1):S1-S196

69. McIntyre HD, Colagiuri S, Roglic G, Hod M. Diagnosis of GDM: A suggested consensus. Best Pract Res Clin Obstet Gynaecol 2015;29(2):194-205. https://doi.org/10.1016/j.bpobgyn.2014.04.022

Accepted 5 April 2019 